\title{
Simulation Study of a New Approach for Field Weakening Control of PMSM
}

\author{
Mohamed Taha Elsayed ${ }^{\dagger}$, Osama Ahmed Mahgoub*, and Sherif Ahmed Zaid* \\ $\dagger *$ Dept. of Electrical Power and Machines, Cairo University, CGiza, Egypt
}

\begin{abstract}
In this paper, the different techniques for the field weakening, also known as constant power speed range (CPSR) operation, for permanent magnet synchronous motor (PMSM) will be introduced and analysed. Field weakening of PMSM, can be done using either vector control (VC) or conventional phase in advance (CPA). Implementation of these techniques depending on some features and constrains. Most of these features and constrains came from the motor parameters. One of these constrains is the motor inductance which determining whether the motor can be driven in the CPSR or not. A new approach for the field weakening will be discussed and to be verified to overcome this constrain. The new approach will be verified through both techniques VC and CPA.
\end{abstract}

Key Words: CPA, CPSR, MTPA, PMSM

\section{INTRODUCTION}

Due to the advantages of the Permanent Magnet Synchronous Motors (PMSM) the application of PMSMs has greatly broadened [1]. The zero rotor copper loss is that results in higher efficiency, the high torque and output power/volume that results in compact design and the simplicity in construction and maintenance are some of the PMSM advantages. Robotics, aerospace, power tools, generation with renewable energy source, various medical equipment and electric/hybrid vehicles etc are some of the applications that can be established based on PMSM. Because of its many advantages, the permanent magnet machines are preferred over other traditional machines such as brush commutated DC motor, synchronous motor and induction motor especially for highly efficient servo and variable speed drive applications [1]. PMSM control can be controlled using different approaches; scalar control and vector control are possible methods for PMSM motors control [2]. PMSM can be controlled using sensor [3] or sensorless method [4]. PMSM are widely used in traction application because the wide range of the flux weakening control [5], [10]. The constant power speed range (CPSR) for PMSM has gained more interest since many years [5], [11]-[17]. CPSR for PMSM usually done using vector control (VC) [5], [11] or conventional phase in advance (CPA) [11]-[17].

CPSR can be infinite or finite based on the machine parameters. The large winding inductance machines are having

\footnotetext{
Manuscript received Jun. 28, 2011; revised Dec. 1, 2011

Recommended for publication by Associate Editor Kyeong-Hwa Kim.

$\dagger$ Corresponding Author: mohamd.taha@gmail.com

Tel: +202-0142896599, Fax: +202-516-8855, Cairo University

* Dept. of Electrical Power and Machines, Cairo University, Egypt
}

infinite CPSR while the small winding inductance machines are having finite CPSR. Large winding inductance machines can be directly controlled for infinite CPSR operation [18] without any additional elements; however the small winding inductance machines can be controlled for infinite CPSR with external inductance or extra power electronics elements. Direct current control is playing the main rule in the CPSR [19]. The complete analysis in this paper will concentrate on the surface permanent magnet synchronous motor; however same analysis can be done with the internal PMSM [5].

\section{PM Machines Configurations}

In a Permanent Magnet (PM) machine, the field excitation comes from the permanent magnet pole pieces. Depending on working principles, the PM machine can be categorized broadly into three main groups; brush commutated PMDC machines, brushless PMDC machine and brushless PMAC or PM Synchronous Machine (PMSM). The brush-commutated PMDC machine is the DC machine in which electromagnetic field has been replaced by the permanent magnet field. In such machines, permanent magnet poles are situated on the rotating part and the stator consists of three-phase windings that are fed with square waveforms from three-leg converters. The switching of the converter is controlled in such a way that at one time only two phases conduct. This electronic commutation scheme is functionally equivalent to the mechanical brush commutation of the DC machine. Hence, this type of PM DC machines is known as brushless PMDC machines or square-wave PMDC machines. The brushless PM DC machine is preferred for many applications because of its low maintenance, high efficiency and relatively simple switching scheme. The brushless PM AC machine also has permanent 


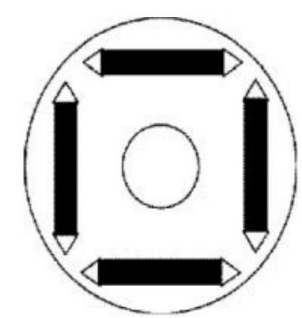

(a)

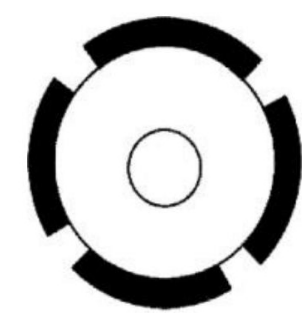

(b)
Fig. 1. Cross-section of the (a) IPM rotor (b) Surface Permanent Magnet rotor

magnet poles in the rotating part and the stator or armature consists of the three-phase, sine-distributed windings. The machine operates with the principle of synchronous rotating magnetic field, hence, they are also known as PM Synchronous Machine (PMSM) [5].

\section{PMSM ROTOR CONFIGURATIONS}

The PM synchronous machines are built with a number of rotor configurations. Among them, interior and surface magnet rotors are the two most commonly used configurations. In the interior permanent magnet (IPM) structure, magnet poles are buried inside the rotor where as in the surface magnet rotor, the magnet poles are glued to the rotor surface as shown in the Fig. 1(a) and (b). In this paper implementation of CPSR on the surface-PMSM will be discussed, however same concept can be modified and implemented for IPM also.

\section{MAThematicAl MOdEL OF A PMSM FOR VECTOR CONTROL}

The mathematical model of a PMSM drive can be described by the following equations in asynchronously rotating rotor $\mathrm{d}$ q reference frame as [2]-[5],

$$
\begin{aligned}
& v_{d}=R_{s} i_{d}+\frac{d \phi_{d}}{d t}-\omega_{e} \phi_{q} \\
& v_{q}=R_{s} i_{q}+\frac{d \phi_{q}}{d t}+\omega_{e} \phi_{d}
\end{aligned}
$$

And,

$$
\begin{aligned}
\phi_{d} & =\left(L_{l d}+L_{m d}\right) i_{d}+\phi_{P M} \\
\phi_{d} & =L_{d} i_{d}+\phi_{P M} \\
\phi_{q} & =\left(L_{l q}+L_{m q}\right) i_{q}=L_{l q} i_{q}
\end{aligned}
$$

Where;

$$
\begin{array}{ll}
R_{s} & : \text { Stator winding resistance [Q] } \\
i_{d}, i_{q} & : \text { d and q axes currents [A] } \\
v_{d}, v_{q} & : \text { d and q axes voltages [V] } \\
\phi_{d}, \phi_{q} & : \text { d and q axes stator flux linkage }[\mathrm{Wb}] \\
L_{l d}, L_{l q} & : \text { d and q axes leakage inductance }[\mathrm{H}] \\
L_{m d}, L_{m q} & : \text { d and q axes magnetizing inductance }[\mathrm{H}] \\
L_{d}, L_{q} & : \text { d and q axis stator inductances }[\mathrm{H}] \\
\omega_{e} & : \text { Electrical speed in rad/sec } \\
\omega_{r} & : \text { Mechanical rotor speed in } \mathrm{rad} / \mathrm{sec} \\
P & : \text { number of pole pairs }
\end{array}
$$

Equations 1 and 2 can be rewritten as;

$$
v_{d}=R_{s} i_{d}+L_{d} \frac{d i_{d}}{d t}-\omega_{e} L_{q} i_{q}
$$

$$
v_{q}=R_{s} i_{q}+L_{q} \frac{d i_{q}}{d t}+\omega_{e} L_{d} i_{d}+\omega_{e} \phi_{P M}
$$

Where;

$$
\omega_{e}=P \omega_{r}
$$

At steady state;

$$
\begin{gathered}
v_{d}=R_{s} i_{d}-\omega_{e} L_{q} i_{q} \\
v_{q}=R_{s} i_{q}+\omega_{e} L_{d} i_{d}+\omega_{e} \phi_{P M}
\end{gathered}
$$

The well-known electro-magnetic torque equation of the electric machine in the $\mathrm{d}-\mathrm{q}$ synchronous reference frame is;

$$
T_{e}=\frac{3}{2} p\left(\phi_{d} I_{q}-\phi_{q} I_{d}\right) .
$$

This equation can be expressed in terms of machine parameters of the PM machine as:

$$
T_{e}=\frac{3}{2} p\left[\phi_{P M} I_{q}+\left(L_{d}-L_{q}\right) I_{d} I_{q}\right] .
$$

In surface PMSM $L_{d}=L_{q}=L_{s}$, equation 11 can be reduced to:

$$
T_{e}=\frac{3}{2} p \phi_{P M} I_{q}
$$

\section{Voltage AND CURRENT Limits OF OPERATION OF PMSM WITH VECTOR CONTROL}

The field weakening control technique must maintain the voltage and current within the limit of the system for the satisfactory performance of the drive system. The current limit in the drive system comes from the rating of the machine and inverter switches. On the other hand, voltage is limited by the available DC link voltage of the system which overcomes the back EMF, reactance and resistance drops of the machine [5], [11], [12]. The locus of the current limit in the d-q plan forms a circle as it is shown in Fig. 2(a), and it is described as;

$$
I_{s}=\sqrt{I_{q}^{2}+I_{d}^{2}} \leq I_{s m}
$$

The voltage limit is expressed as;

$$
V_{s}=\sqrt{V_{q}^{2}+V_{d}^{2}} \leq V_{s m}
$$

Neglecting the stator resistance and considering $L_{q}=L_{d}+L_{s}$ for the surface-PMSM, equations 8 and 9 reforming the previous equation to be rewritten as;

$$
\left(L_{s} I_{q}\right)^{2}+\left(\phi_{p m}+L_{s} I_{d}\right)^{2}=\left(\frac{V_{s m}}{\omega_{e}}\right)^{2} .
$$

Therefore, equation 15 represents the voltage relations in terms of the currents $i_{d}$ and $i_{q}$. This relation can then be represented in the synchronously rotating frame $i_{q}-i_{d}$ plane as a circle centered at $\left(-\frac{\phi_{p m}}{L}, 0\right)$ and with radius of $\left(-\frac{V_{s m}}{L_{s} \omega_{e}}\right)$. The radius is proportional to the applied armature voltage Vsm and inversely proportional to rotor speed $\omega_{r}$. It is important to notice that for a given $V_{s m}$, the radius of the circle decreases as the speed increases. Fig. 2(b), shows the voltage limit circles for fixed $V_{s m}$. Note that in Fig. 2(b), $\omega_{r 3}>\omega_{r 2}>\omega_{r 1}$.

In equation 15 , suppose that $\omega$ r goes to infinity, at this speed the machine will not be able to develop a torque so iq will be zero and id will be $\left(-\frac{\phi_{p m}}{L}\right)$. The value of $\left(-\frac{\phi_{p m}}{L}\right)$ is 


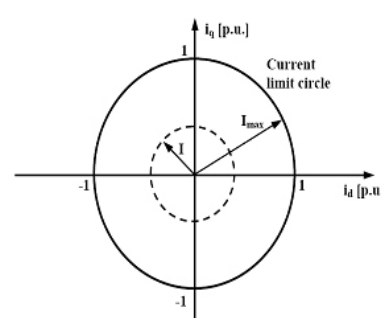

(a)

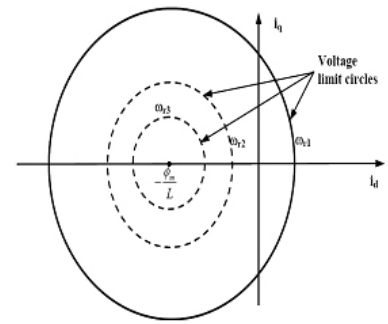

(b)
Fig. 2. (a) Normalized current limit circle in the synchronously rotating reference frame. (b) Voltage limit circles in the synchronously rotating reference frame.

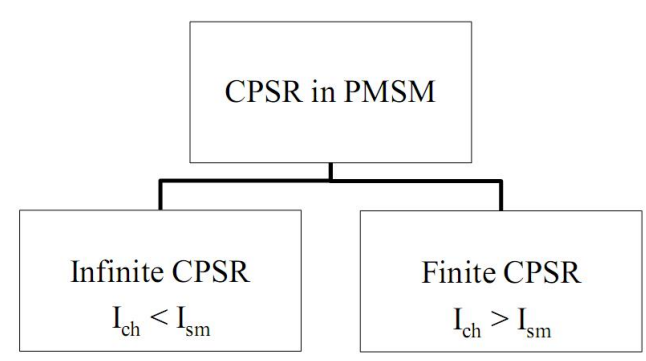

Fig. 3. PMSM categories based on $I_{c h}$.

called the characteristic current $\left(I_{c h}\right)$ and it is a very important factor for determining if this machine can be used for a wide CPSR or not [12]-[14]. It is very clear that $I_{c h}$ is a machine parameters dependant value. From this point of view PMSM can be divided into two groups based on CPSR capability as shown in Fig. 3.

As the speed increases, the radius of the voltage limit circle decreases. The radius then goes to zero when the speed goes to infinity. Therefore, there will always be a voltage limit circle within which the machine can operate. However, as discussed previously, the current limit also must be satisfied, and therefore, the operating current vector locus is the area defined by the intersection of the two limit circles as shown in Fig. 4(a). Therefore, if $I_{S m}\left|\Phi_{P M} / L_{S}\right|$, which means that the center of the voltage limit circle will be either in the current limit circle or inside of it, then the CPSR is theoretically infinite. On the other hand, if $I_{s m}<\left|\Phi_{P M} / L_{S}\right|$, then the intersection will vanish at a finite value of $\omega_{r}$. From the previous discussion; if the inductance is large enough, the constant power speed range

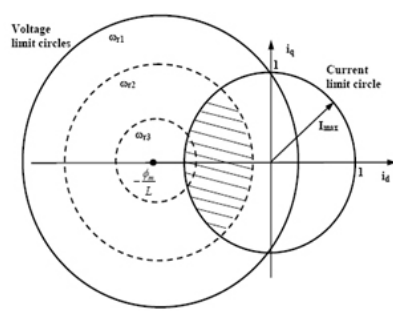

(a)

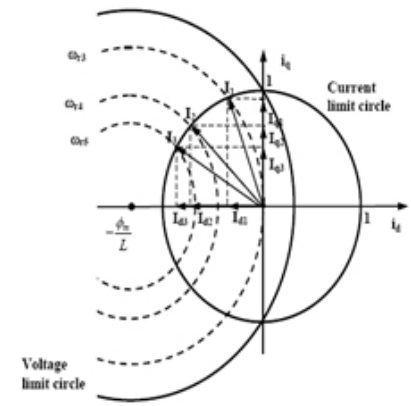

(b)
Fig. 4. (a) Current circle limit and voltage limit circle for PMSM drive system. (b) Current trajectory for vector control of PMSM operating in CPSR with field weakening.

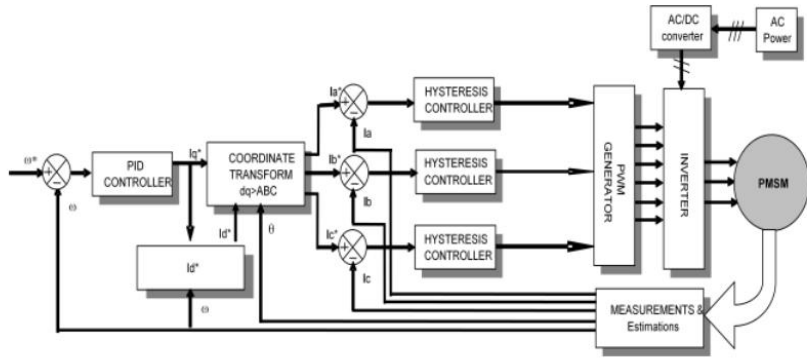

Fig. 5. Vector Control block diagram.

can be infinite. There will be a maximum speed at which the machine can develop rated torque. This speed is called critical speed $\omega_{r c}$ and it is the limit of CPSR. Therefore, the constant power range then starts at $\omega_{r b}$ and ends at $\omega_{r c}$ [3]. Where;

$$
\omega_{r c}=\frac{\phi_{P M}^{2}+\left(L_{s} I_{s m}\right)^{2}}{\phi_{P M}^{2}-\left(L_{s} I_{s m}\right)^{2}} \omega_{r b}
$$

\section{IMPLEMENTATION OF MTPA AND CPSR USING VECTOR CONTROL}

Fig. 5 shows the block diagram of the constant torque operation range (CTOR) and CPSR vector control. Speed controller is based on the following equations [3]. $i_{q}$ reference will be directly extracted from the speed controller while the id reference will be zero, for MTPA, if $\omega_{r}<=\omega_{r b}$ else it will be extracted from equations 17 [11].

$$
i_{d}^{*}=-\frac{1}{L_{s}}\left(\phi_{p m}-\frac{V_{s m}}{\left|\omega_{e}\right|}\right)+\frac{\left|i_{q}^{*}\right|}{I_{s m} L_{s}}\left(\phi_{p m}-\frac{V_{s m}}{\omega_{b}}\right)
$$

\section{IMPLEMENTATION OF CPSR USING VECTOR CONTROL-NEW APPROACH}

Equation 17 is the main equation for the new approach. Suppose that there is a motor that has $I_{s m}<\left|\Phi_{P M} / L_{S}\right|$, this means that this motor can't be controlled for a wide CPSR. As it was described before the solution of this problem theoretically can be done using one of the next two main methods. Method 1, increasing, $\Phi_{P M}$, which means changing the motor construction and rearranging the permanent magnets inside the rotor [1]. Method 2 is to increase the stator inductance, $L_{S}$, either by adding a real series inductance or a virtual series inductance. Virtual series inductance means adding a power electronic device that acting as a series inductance [12], [14][17]. Fig. 6 shows the Dual Mode Inverter Control (DMIC) topology, The DMIC interfaces the output of a common voltage source inverter (VSI) to the PMSM through an ac voltage controller and acts as a series inductance [15]. The AC voltage controller consists of three pairs of anti-parallel silicon controlled rectifiers (SCRs), one anti-parallel SCR pair in series with each winding of the motor [5]-[10]. Fig. 7 shows the Per-phase fundamental frequency model for the DMIC with PMSM as concluded in [15]. It is very clear from Fig. 7 that the back to back thyristors are acting as a series inductance with the PMSM [15]. This extra value of the inductance will limit the current at CPSR to be always less than the Ism. 


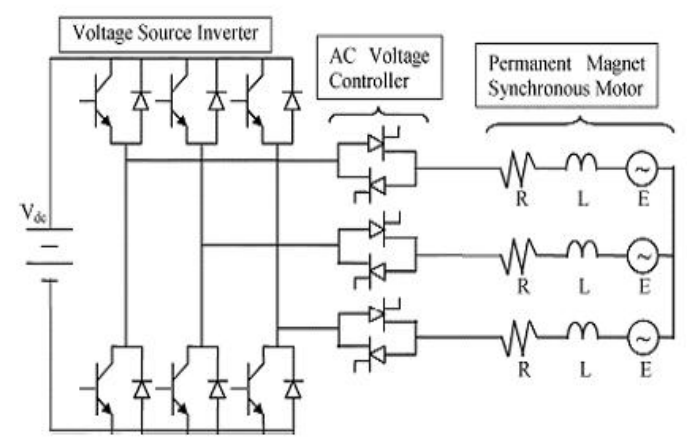

Fig. 6. DMIC inverter topology.

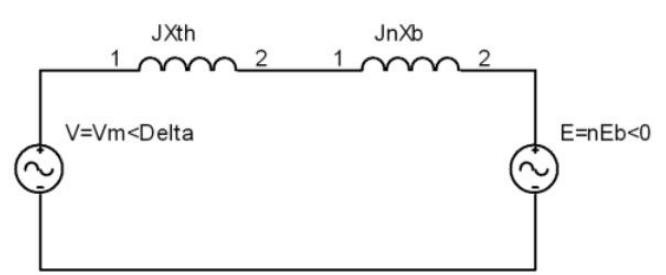

Fig. 7. Per-phase fundamental frequency phasor model for constant power mode.

\section{Calculating the Value of the Series INDUCTANCE}

First, it should be very clear that adding more inductance is not unlimited because adding more inductance in series with PMSM may require increases of the $V_{d c}$ due to the voltage drop in the external inductances, and it will also make the whole system bulky. By the way there are two ways for calculating the series inductance required. First one of them is simple and it is based on the $I_{c h}$. The main objective of this method is to make $I_{c h}$ less than Ism. So, the calculation will be based on the following equation;

$$
\begin{aligned}
I_{s m} & >I_{c h}^{\text {new }} \\
I_{s m} & >\frac{\phi_{P M}}{L_{s}+L_{\text {new }}} .
\end{aligned}
$$

From equation $18 L_{\text {new }}$ can be easily calculated and in this case the speed will be theoretically infinite. Method 2 will be based on equation 16. This method is a finite CPSR method. In method 2 the needed inductance will be calculated based on the needed CPSR range, for $\mathrm{K}$ times $\omega_{r b}$ speed $\left(\omega_{\text {rnew }}=K^{*} \omega_{r b}\right)$, where $\omega_{r b}$ is the mechanical rated speed in $\mathrm{rad} / \mathrm{sec}$. So equation 16 will be;

$$
K=\frac{\phi_{P M}^{2}+\left(\left(L_{s}+L_{n e w}\right) I_{s m}\right)^{2}}{\phi_{P M}^{2}-\left(\left(L_{s}+L_{n e w}\right) I_{s m}\right)^{2}} .
$$

\section{The New APPROACH}

From the previous analysis, it can be concluded that the effect of the added inductance is to limit the motor current from exceeding the rated current Ism. Equation 17 shows that Id reference is function of the stator inductance $L_{s}$. The new approach supposing that instead of adding a real series inductance with the motor, the inverter will be forced to act as an AC supply with series inductance. Applying this idea is either by choosing a certain switching pattern for the inverter

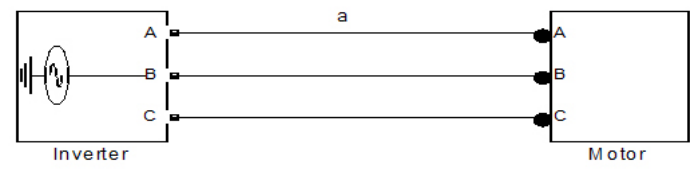

(a)

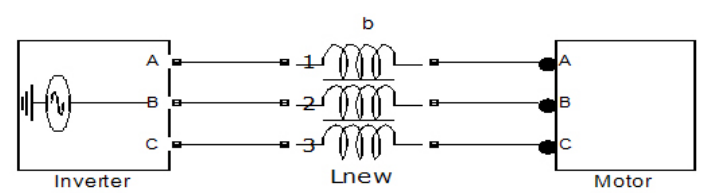

(b)

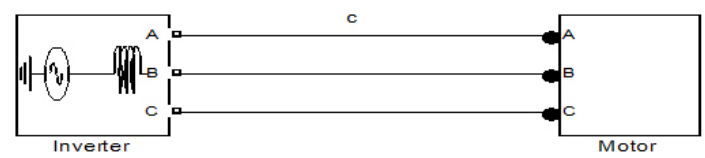

(c)

Fig. 8. (a) Inverter-motor model without adding inductance.(b) inverter-motor model with $L_{n e w}$ inductance. (c) inverter-motor model with inverter acting as supply with series inductance.

to do this role or by selecting the proper reference values to force the inverter to act as an AC supply with series inductance. Selecting the proper reference value is much clear and easier.

For more clarification; suppose that the PWM technique to be used is the sinusoidal pulse width modulation (SPWM). To generate the PWM; two inputs are required for this technique. First is the frequency of the reference signal and the second is the modulation index. The modulation index is calculated from equation 20 where $V$ is the required fundamental of the output voltage from the inverter [12]. So, for the new approach the modulation index will be changed properly to make the inverter acting as AC supply with series inductance by using $V_{\text {new }}$ which is $\left(V-V_{\text {Lnew }}\right)$ to calculate the modulation index. Where $V_{\text {Lnew }}$ is the voltage drop on the virtual inductance.

$$
V=\frac{1}{\sqrt{2}} * m_{a} * \frac{V_{d c}}{2} .
$$

The reference values for the vector control here are $I_{q}$ which came directly from the difference between the actual and reference speed and $I_{d}$ reference that is to be selected as equation 21 to achieve this role;

$i_{d}^{*}=-\frac{1}{\left(L_{s}+L_{\text {vnew }}\right)}\left(\phi_{p m}-\frac{V_{s m}}{\left|\omega_{e}\right|}\right)+\frac{\left|i_{q}^{*}\right|}{I_{s m}\left(L_{s}+L_{\text {vnew }}\right)}\left(\phi_{p m}-\frac{V_{s m}}{\omega_{b}}\right)$.

By this way the stator current will be limited to the desired value without adding any real inductance where the virtual inductance $L_{\text {vnew }}=L_{\text {new }}$ calculated in the previous section. Fig. 8(c) shows the equivalent model of the new approach. This approach has been tested using MATLAB and results insured the previous analysis.

\section{CONVENTIONAL PHASE IN ADVANCE TECHNIQUE FOR PMSM}

Above base speed, the internal back-EMF exceeds maximum available supply voltage. Thus as the speed of the 


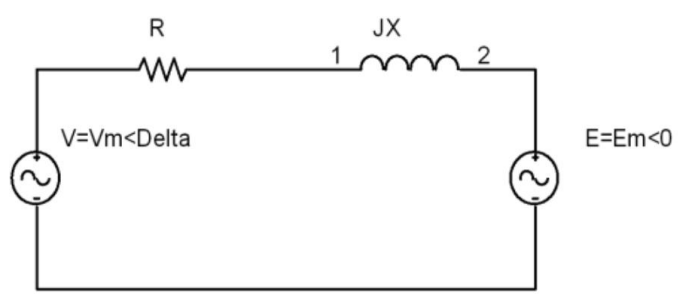

Fig. 9. Fundamental frequency model.

motor approaches the base speed, the ability of an inverter to force current into motor winding reduces. This causes torque reduction and ultimately puts limitation on the achievable maximum speed. Above base speed, this technique results in an application of voltage to the motor winding when the instantaneous value of the back EMF of the corresponding motor winding is less than the applied voltage [13].

\section{Fundamental Frequency Model}

Fig. 9 shows a per-phase, fundamental frequency model of a surface PM motor driven by a voltage source inverter. This is equivalent to one of the three phases. The first part (DC supply + an inverter section) is replaced by the resultant, inverter output AC voltage Vector $V \angle \delta$ represents line-to-neutral supply voltage at fundamental frequency. The frequency of this supply voltage is the same as the frequency of the reference waveform while the RMS magnitude of the supply voltage depends on the modulation index for the SPWM.

Neglecting the armature resistance; from Fig. 9, the voltage magnitude $\mathrm{V}$ can be written as;

$$
V \angle \delta=n * E_{b} \angle 0^{\circ}+j * n * X_{b} * \bar{I}
$$

And the current vector can be written as;

$$
\begin{gathered}
\bar{I}=\frac{V}{n * X_{b}} \sin \delta+j *\left(\frac{E_{b}}{X_{b}}-\frac{V}{n * X_{b}} \cos \delta\right) \\
\bar{I}=I_{r}+j I_{x}
\end{gathered}
$$

Where;
$\mathrm{P} \quad$ :Number of pole pairs
$\mathrm{N}_{b} \quad$ :relative speed $=\omega_{r} / \omega_{r b}$
$\mathrm{X}_{b} \quad$ :Reactance at base speed
$\mathrm{E}_{b} \quad$ :RMS value of the phase-to-neutral back-emf at base speed

It can be seen from Equation (24) that this stator current has two parts; real part $I_{r}$ which is responsible for mechanical torque production, and Imaginary part $I_{x}$. Here $I_{r}$ is the component of motor current which is in phase with the backEMF. This component is like a q-axis current component in the d-q model and it can be referred to as a torque producing current component. $I_{x}$ is the component of a phase current that is orthogonal to the back-EMF and produces no net torque production. This component is like a d-axis component of the current in the d-q model and can be referred to as a field weakening current [11].

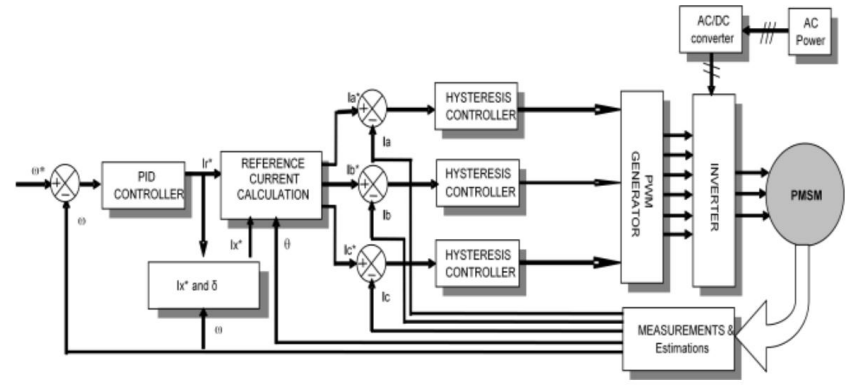

Fig. 10. Vector Control block diagram.

TABLE I

MOTOR PARAMETERS

\begin{tabular}{|l|l|}
\hline Motor rated power Rated $\left(\mathrm{P}_{r}\right)$ & 3-phase, 250watt \\
\hline voltage & $125 \mathrm{~V}$ \\
\hline Rated current & $2.5 \mathrm{~A}$ \\
\hline Rated frequency & $270 \mathrm{~Hz}$ \\
\hline Pole pair number $(\mathrm{P})$ & 4 \\
\hline Stator inductance, $\mathrm{L}_{s}\left(\mathrm{~L}_{q}=\mathrm{L}_{d}=\mathrm{L}_{s}\right)$ & $12.8 \mathrm{mH}$ \\
\hline Stator resistance, $\mathrm{R}$ & $6 \Omega$ \\
\hline Magnetic flux constant, $\phi_{P M}$ & $21.5 \mathrm{~V} / 1000 \mathrm{rpm}$ \\
\hline
\end{tabular}

\section{Voltage AND CURRENT LIMITS OF OPERATION OF PMSM WITH CPA}

Voltage limit for CPA is the maximum voltage for the motor terminals $V_{s m}$. However the current limits can be seen from the following analysis.

$$
\begin{aligned}
& \lim _{n \rightarrow \infty} \bar{I}=\lim _{n \rightarrow \infty}\left[\frac{V}{n * X_{b}} \sin \delta+j *\left(\frac{E_{b}}{X_{b}}-\frac{V}{n * X_{b}} \cos \delta\right)\right] \\
& \lim _{n \rightarrow \infty} I_{r}=\lim _{n \rightarrow \infty}\left[\frac{V}{n * X_{b}} \sin \delta\right]=0 \\
& \lim _{n \rightarrow \infty} I_{x}=\lim _{n \rightarrow \infty}\left[j *\left(\frac{E_{b}}{X_{b}}-\frac{V}{n * X_{b}} \cos \delta\right)\right]=\frac{E_{b}}{X_{b}}=\frac{\phi_{P M}}{L} .
\end{aligned}
$$

Equation 25 shows that, same characteristic current $I_{c h}$ is the current limit in case of the CPA, same as the vector control Fig. 2(b).

\section{IMPLEMENTATION OF MTPA AND CPSR USING CPA}

Fig. 9 shows the block diagram of the CTOR and CPSR vector control. Speed controller is based on the following equations. $I_{r}$ reference will be directly extracted from the speed controller while the $I_{x}$ reference will be zero, for MTPA; if $\omega_{r} \omega_{r b}$ else it will be extracted from equation 17.

$$
\left.I_{x}^{*}=\left(\frac{E_{b}}{X_{b}}-\frac{V_{s m}}{n * X_{b}} \cos \delta^{*}\right)\right]
$$

Where,

$$
\delta^{*}=\sin ^{-1}\left(\frac{n * X_{b} * I_{r}^{*}}{V_{s m}}\right)
$$

\section{Simulation Results}

A fixed reference speed and torque profile has been applied to the motor for all cases. First $0.2 \mathrm{sec}$. the rated speed 4050 rpm and torque $0.6 \mathrm{~N} . \mathrm{m}$, the speed of $6000 \mathrm{rpm}\left(1.5 * \mathrm{n}_{\text {rated }}\right)$ for next $0.2 \mathrm{sec}$, then speed of $8000 \mathrm{rpm}$ and finally 10000 rpm $\left(2.5^{*} \mathrm{n}_{\text {rated }}\right)$. The fixed reference torque profile is being 

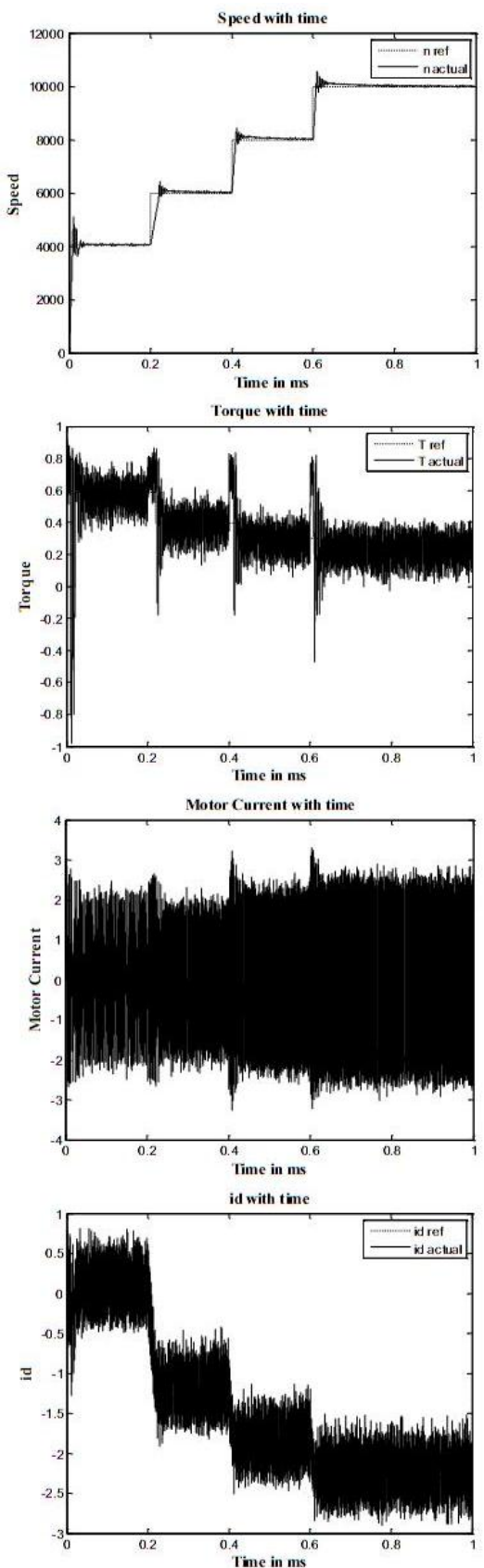

iq with time

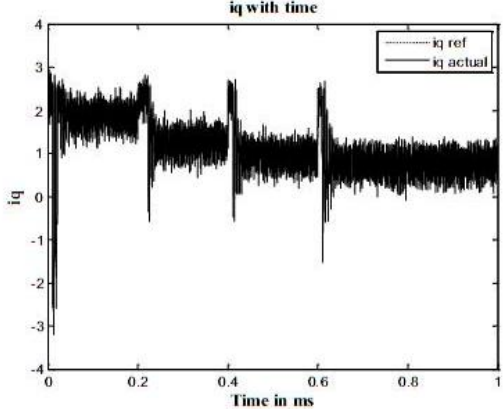

Fig. 11. Vector control simulation results for Fig. 8(a).
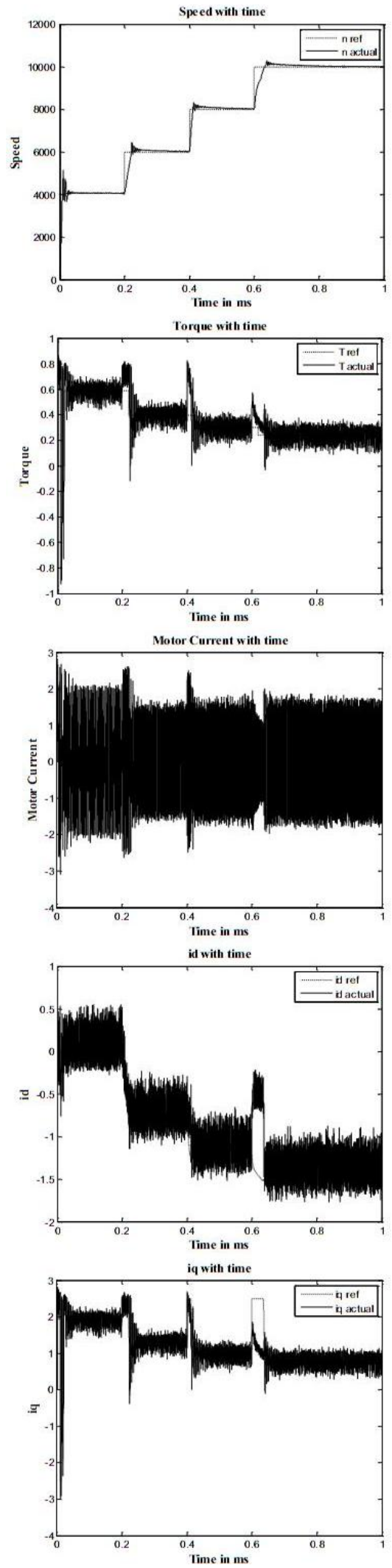

Fig. 12. Vector control simulation results for Fig. 8(b) 
controlled by the equation $T=\left(P_{r} / \omega_{r}\right)$ to achieve the constant power range after the CTOR.

Simulation results in Fig. 11, 12 and 13 show the simulation results of the vector control implementation on the PMSM in three different configurations scheme. The configuration scheme one shown in Fig 8.a, is the normal inverter-motor scheme without any additional components. Fig. 11 shows the simulation results for the first scheme where the actual speed has followed the reference speed, motor current was the rated current during the first $2 \mathrm{sec}$ where the motor is running at the rated power and rated speed. It is very clear from the motor current that it exceeds the rated value while the motor is trying to deliver the rated power at all other speeds above the rated speed. The rest of the figures shows that the direct and quadrature currents also following the reference currents. One important note; that at rated speed and any speed below it the direct current is equals zero which verifying the MTPA concept at the CTOR.

Second scheme, in which an additional real inductance $\left(L_{\text {new }}\right)$ added in series with the motor, is shown in Fig. 8(b). Fig. 12, shows the simulation results for the second scheme. It is very clear, from the simulation results that the actual speed has followed the reference speed also; motor current was the rated current during the first $2 \mathrm{sec}$. where the motor is running at the rated torque and the rated speed. However, the current doesn't exceed the rated value while the motor is delivering the rated power at all speeds above the rated speed. Third scheme in Fig. 8(c) is the new approach, in which the inverter is required to act as an AC source in series with virtual inductance $\left(L_{\text {vnew }}\right)$.

Therefore, this inductance will be added to the equation (19) which is governing the direct current. Fig. 13 shows the simulation results for the third scheme. It is very clear from the simulation results that the motor performance in the third scheme is very similar to the second scheme. This means that the virtual inductance $\left(L_{\text {vnew }}\right)$ acted perfectly as the real inductance. However, in the thirds scheme no need for additional real inductance that will increase the overall system size.

Simulation results in Fig. 14, 15 and 16 show the simulation results of CPA implementation on PMSM in three different configurations scheme. The results are confirming the simulation results from the implementation of the vector control.

Fig. 14 shows the simulation results of first scheme with almost same results from vector control, which means the motor current exceeding the rated value as the motor trying to deliver the rated power above the rated speed. figures 15 and 16 , representing second and third schemes and they are almost same. This means that the virtual inductance succeeded to act as the real inductance here also with all benefits of the real inductance in no increasing in the overall system size.

\section{CONCLUSIONS}

The simulation study in this paper verified that; CPSR can be achieved using either the vector control technique or CPA technique. Voltage and current can be maintained within limits. Current limit can be achieved either by using an additional 

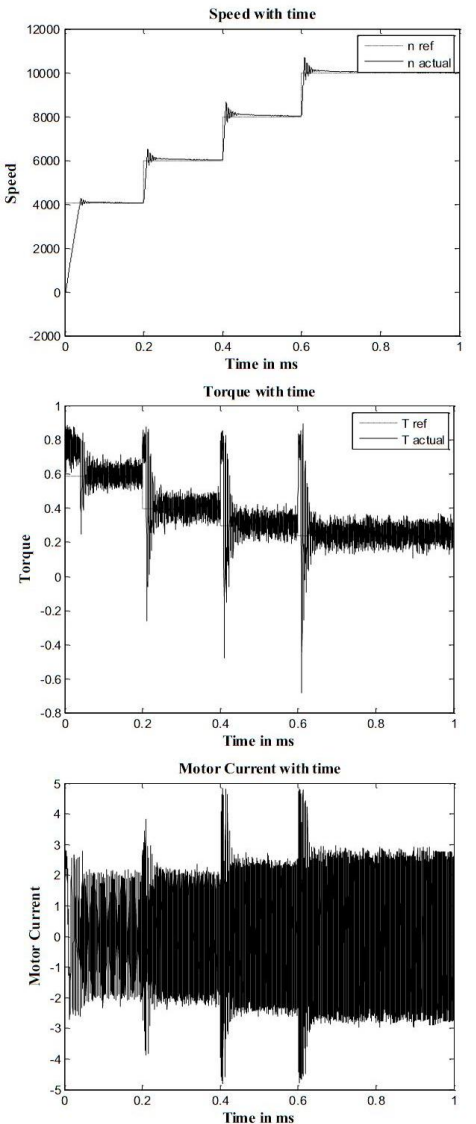

Fig. 14. CPA simulation results for Fig. 8(a).
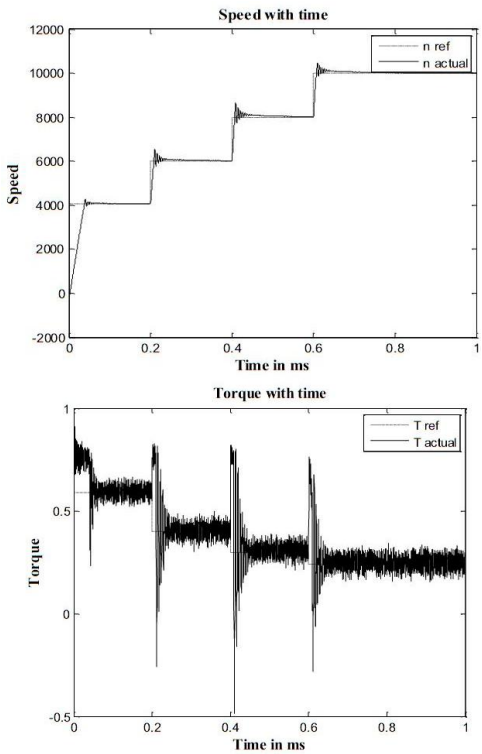

Motor Current with tim

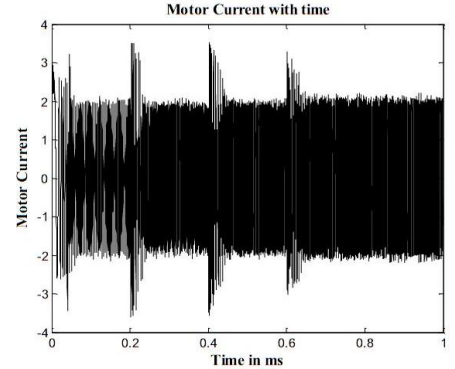

Fig. 15. CPA simulation results for Fig. 8(b).
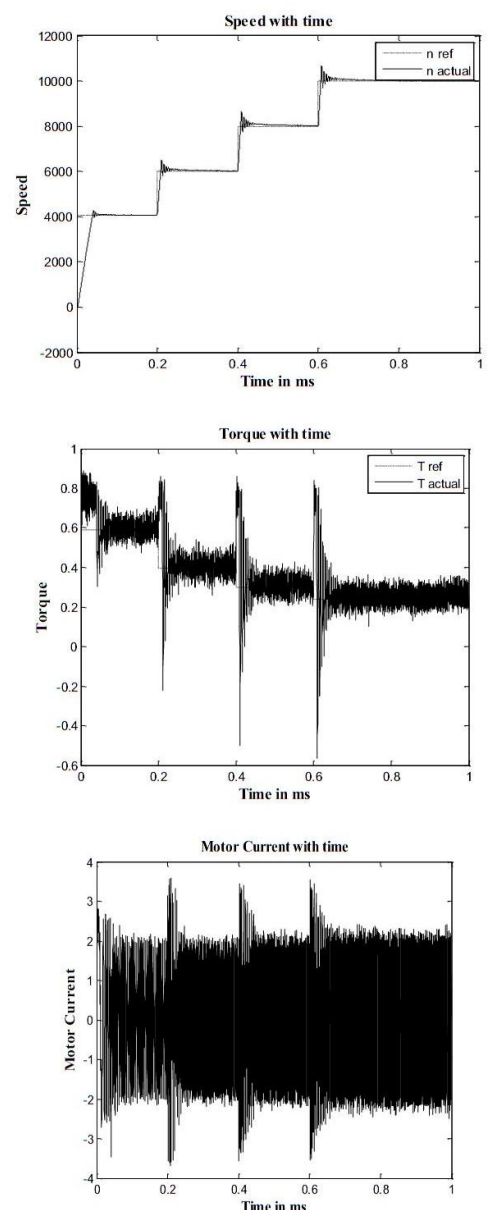

Fig. 16. CPA simulation results for Fig. 8(c).

inductance or by the new approach of the virtual inductance. The new approach of the virtual inductance is a cost effective solution; achieving the current limit and keeping the overall system size the same. The maximum torque per ampere can be achieved by forcing the Id in vector control or Ix in CPA to be zero while the motor working in the CTOR. Motors with lower inductance can be driven for wide CPSR without adding extra inductance either by vector control or CPA.

\section{REFERENCES}

[1] P. Pillay and R. Krishnan, "Application characteristics of permanent magnet synchronous and brushless DC motors for servo drives," IEEE Trans. Ind. Appl.,, Vol. 27, No. 5, pp. 986-996, Sep./Oct. 1991.

[2] M. Stulrajter, V. Hrabovcova, and M. Franko, "Permanent magnets synchronous motor control theory," Journal of ELECTRICAL ENGINEERING, Vol. 58, No. 2, 79-84, 2007,

[3] M. Kaewjindam W Konghirun, “A dsp - based vector control of pmsm servo drive using resolver sensor," TENCON 2006, pp. 1-4, 2006.

[4] K.-L. Kang, J.-M. Kim, K.-B. Hwang, and K.-H. Kim, "Sensorless control of PMSM in high speed range with iterative sliding mode observer," Applied Power Electronics Conference and Exposition, APEC '04., Vol. 2, pp. 1111-1116, 2004.

[5] R. Dutta, "A segmented interior permanent magnet synchronous machine with wide field-weakening range," $\mathrm{PhD}$ thesis, The University of New South Wales, Aug. 2007.

[6] O. Mohammed "Sensorless control of brushless dc motor", PhD thesis,PlaceNameplaceCairo PlaceTypeUniversity, Sep. 2004.

[7] B. K. Bose, Modern power electronics and ac drives, Prentice Hall, 2002.

[8] M. A. Rahman and P. Zhou, "Analysis of brushless permanent magnet synchronous motors," IEEE Trans. Ind. Electron., Vol. 43, No. 2, pp. 256-267, Apr. 1996. 
[9] M. A. Hoque, C. Butt and M. A. Rahman, "A novel approach for mtpa speed control of ipmsm drive," Second International Conference on Electrical and Computer Engineering ICECE 2002, 2002.

[10] M. Meyer and J. Boecker, "Optimum control for interior permanent magnet synchronous motors (ipmsm) in constant torque and flux weakening range," 12th International Power Electronics and Motion Control Conference, pp. 252-286, 2006.

[11] J. O. P. Pinto, "Analysis of extended constant power speed range of the permanent magnet synchronous machine driven by dual mode inverter control", $\mathrm{PhD}$ thesis, The University of Tennessee, CityplaceKnoxville, August, 2001.

[12] N. A. Patil, "Field weakening operation of ac machines for traction drive applications", PhD thesis, The University of Tennessee, CityplaceKnoxville, August, 2009.

[13] J. S. Lawler, "Application of dual-mode inverter control to commercially available radial-gap permanent magnet motors - vol. i," final report for CRADA number ORNL 04-0691, May, 2006.

[14] J. S. Lawler, "Control of surface mounted permanent magnet motors with special application to fractional-slot motors with concentrated windings", ORNL/TM-2007/007, July, 2007.

[15] A. M. E.-R. Donald, placeW. Novotny, and T. M. Jahns, "A simple model for flux weakening in surface pm synchronous machines using back-to-back thyristors," IEEE power electronics letters, Vol. 2, No. 2, Jun. 2004.

[16] J. S. Lawler, J. M. Bailey, J. W. McKeever, and J. Pinto, "Extending the constant power speed range of the brushless dc motor through dualmode inverter control," IEEE Trans. Power Electron., Vol. 19, No. 3, pp. 783-793, May 2004.

[17] J. S. Lawler, J. Milton Bailey, John W. McKeever, and João Pinto, "Minimum Current Magnitude Control of Surface PM Synchronous Machines During Constant Power Operation," IEEE power electronics letters, Vol. 3, No. 2, pp. 53-56, Jun. 2005.

[18] H. Liu, Z. Q. Zhu, E. Mohamed, Y. Fu, and X. Qi "Flux-weakening Control of Non-Salient Pole PMSM Having Large Winding Inductance, counting for Resistive Voltage Drop and Inverter Nonlinearities," IEEE Trans. Power Electron., Vol. PP, No. 99, page. 1, Jun. 2011.
[19] Y. Zhang, L. Xu, M. K. Güven, S. Chi, and M. Illindala, "Experimental verification of deep field weakening operation of a 50-kW IPM machine by using single current regulator," IEEE Trans. Ind. Appl., Vol. 47, No. 1, pp. 128-133, Jan./Feb. 2011.

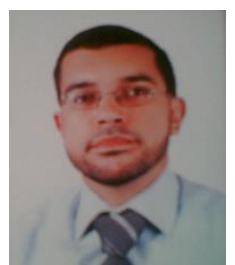

Mohamed Taha Elsayed received his B.S. and M.Sc. in Electrical Engineering from CityplaceCairo University, country-regionEgypt, in 2002 and 2006, respectively. $\mathrm{He}$ is currently a teaching and research assistant in the Department of Electrical Power, Faculty of Engineering, CityplaceCairo University, country-regionEgypt. His current research interests include power electronics and drives.

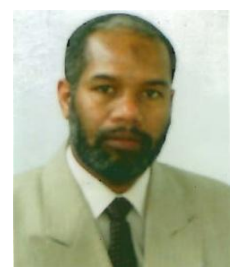

Osama Ahmed Mahgoub received his B.S., M.Sc. and $\mathrm{Ph} . \mathrm{D}$. in Electrical Engineering from CityplaceCairo University, country-regionEgypt, in 1982, 1987 , and 1991, respectively. He is currently a Professor of power electronics in the Department of Electrical Power, Faculty of Engineering, CityplaceCairo University, country-regionEgypt. His current research interests include power electronics converters, motor drives, renewable energy systems, and APFs.

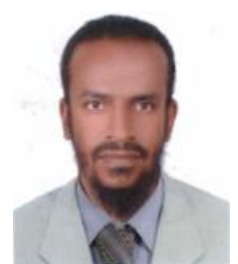

Sherif Ahmed Zaid received his B.S., M.Sc., and Ph.D. in Electrical Engineering from CityplaceCairo University, country-regionEgypt, in 1992, 1996, and 2001, respectively. $\mathrm{He}$ is currently an Instructor of power electronics in the Department of Electrical Power, Faculty of Engineering, CityplaceCairo University, countryregionEgypt. His current research interests include power electronics and drives. 